UNIVERSIDADE DE SÃO PAULO

FACULDADE DE DIREITO

\title{
CONSTITUCIONALISMO EM TEMPOS DE GLOBALIZAÇÃO: \\ A SOBERANIA NACIONAL EM RISCO?
}

ANA PAULA ZAVARIZE CARVALHAL

\author{
SÃO PAULO \\ 2014
}




\section{CONSTITUCIONALISMO EM TEMPOS DE GLOBALIZAÇÃO:}

\section{A SOBERANIA NACIONAL EM RISCO?}

Tese de doutorado apresentada como requisito parcial para a conclusão do curso de Doutorado em Direito, Área Direito do Estado, Subárea Direito Constitucional, sob orientação do Prof. Titular Manoel Gonçalves Ferreira Filho

São Paulo - SP

Faculdade de Direito da USP 2014 
Autorizo a reprodução e divulgação total ou parcial deste trabalho, por qualquer meio convencional ou eletrônico, para fins de estudo e pesquisa, desde que citada a fonte.

CARVALHAL, Ana Paula Zavarize.

Constitucionalismo em tempos de globalização: a soberania nacional em risco? / Ana Paula Zavarize Carvalhal: ; orientador Manoel Gonçalves Ferreira Filho. - São Paulo, 2014.

$280 \mathrm{f}$.

Tese (Doutorado) - Universidade de São Paulo, 2014.

1. Constitucionalismo. 2. Globalização. 3. Soberania. 4. Constitucionalismo Multinível. 5. Interconstitucionalidade. 6. Transconstitucionalismo. 7. Constitucionalismo Global. 
Nome: Ana Paula Zavarize Carvalhal

Título: CONSTITUCIONALISMO EM TEMPOS DE GLOBALIZAÇÃO: A SOBERANIA NACIONAL EM RISCO?

Tese defendida em de de 2014, perante banca examinadora composta pelos professores:

Prof. Titular Manoel Gonçalves Ferreira Filho

Membro

Membro

Membro

Membro 


\section{RESUMO}

Nas últimas décadas surgiram diversas doutrinas sobre possíveis evoluções do constitucionalismo, impulsionadas pelos processos de globalização, regionalização e transnacionalização. Partindo da ideia de crise do Estado moderno e crise da soberania, doutrinadores nacionais e estrangeiros desenvolvem teorias sobre um constitucionalismo sem Estado e sem Constituição, múltiplos constitucionalismos convivendo sem relação hierárquica entre eles. Assim, a partir da análise dos conceitos clássicos e das principais doutrinas sobre as diferentes formas de aproximação entre o direito constitucional e o direito internacional, procura-se avaliar o impacto real da globalização no Estado moderno, em especial para a soberania nacional e o direito constitucional. Busca-se demonstrar que ainda há lugar para a soberania.

Palavras-chaves: Constitucionalismo, Estado moderno, Soberania, Constitucionalismo Global, Direito transnacional, Transconstitucionalismo. 


\begin{abstract}
In recent decades, various doctrines about possible developments of constitutionalism emerged, driven by the process of globalization, regionalization and transnationalization. Starting from the idea of the modern State crisis and sovereignty crisis, domestic and foreign scholars develop theories over a constitutionalism without a state or constitution, multiple constitutionalism coexisting with no hierarchical relationship between them. Thus, from the analysis of classical concepts and the main doctrines about the different ways of approaching the constitutional law and international law, seeks to assess the real impact of globalization in the modern State, especially for national sovereignty and constitutional law. It is quite evident that there is still room for sovereignty.
\end{abstract}

Keywords: Constitutionalism, modern State, Sovereignty, Global Constitutionalism, transnational law, Transconstitucionalism. 


\section{RÉSUMÉ}

$\mathrm{Au}$ cours des dernières décennies, plusieurs doctrines sur les possibles développements du constitutionnalisme ont émergées, entraînées par la mondialisation, la régionalisation et la transnationalisation. À partir de la crise de l'État moderne et de la souveraineté, les chercheurs nationaux et étrangers développent des théories sur un constitutionnalisme apatride et sans Constitution, plusieurs constitucionnalismes coexistant sans aucune relation hiérarchique entre eux. Ainsi, à partir de l'analyse des concepts classiques et les principales doctrines sur les différentes façons d'approcher le droit constitutionnel et le droit international, vise à évaluer l'impact réel de la mondialisation dans l'État moderne, en particulier de la souveraineté nationale et le droit constitutionnel. On vise à démontrer qu'il existe toujours la souveraineté de la chambre.

Mots-clés: Constitutionnalisme, L'Etat moderne, La Souveraineté, Constitutionnalisme Global, Le Droit Transnational, Transconstitucionalisme. 


\section{SUMÁRIO}

INTRODUÇÃO

1. SOBERANIA, GLOBALIZAÇÃO E GOVERNANÇA MUNDIAL 18

1.1. Crise do Estado Moderno? A questão da organização do poder 20

1.2. Crise do Constitucionalismo? A questão da limitação do poder 43

1.3. Crise do Direito Internacional? A questão do compartilhamento do poder ... 60

1.4. Crise da Soberania? A questão da legitimação do poder .... 75

1.5. Síntese Conclusiva do Capítulo 1 106

2. MOVIMENTOS DE APROXIMAÇÃO ENTRE O DIREITO CONSTITUCIONAL E O DIREITO INTERNACIONAL 111

2.1. Constitucionalização do Direito Internacional? Globalização e Ordenamento Jurídico Internacional 113

2.2. Internacionalização do direito constitucional? Globalização e Ordenamento Jurídico Nacional 145

2.3. Constitucionalismo Pós-Nacional? Globalização e Ordenamento Jurídico Transnacional 176

2.4. Constitucionalismo Mundial? Globalização e Ordenamento Jurídico Mundial. 213

2.5. Síntese Conclusiva do Capítulo 2

3. BREVES COMENTÁRIOS SOBRE A INTERNACIONALIZAÇÃO DO DIREITO CONSTITUCIONAL BRASILEIRO 235

3.1. A abertura do Direito Constitucional brasileiro ao Direito Internacional .... 238

3.2. O Direito Constitucional brasileiro e a Corte Interamericana de Direitos .... 248

3.3. STF e Mercosul 271

3.4. STF e Diálogo Constitucional 276

3.5 Síntese Conclusiva do Capítulo 3 284

CONCLUSÃO 287 


\section{ÍNDICE}

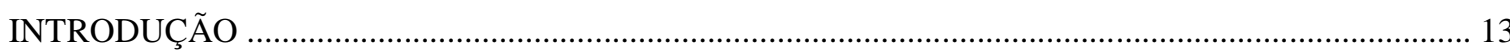

1. SOBERANIA, GLOBALIZAÇÃO E GOVERNANÇA MUNDIAL ............................................ 18

1.1. Crise do Estado Moderno? A questão da organização do poder 20

1.1.1. As Origens do Estado Moderno …………………………………………….... 22

1.1.2. A Evolução do Estado Moderno ……………………………………………….... 25

1.1.2.1. O Estado Absolutista ............................................................................. 26

1.1.2.2. O Estado Constitucional .............................................................................. 27

1.1.2.2.1. O Estado Liberal .......................................................................... 27

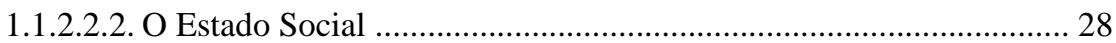

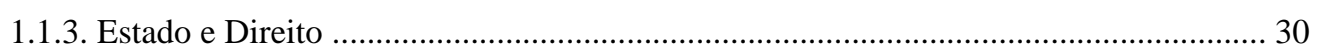

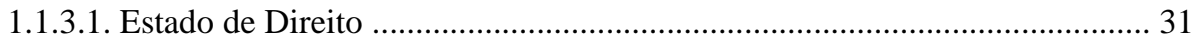

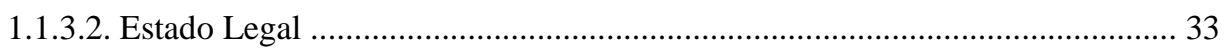

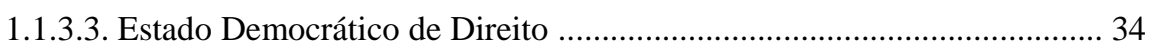

1.1.4. Há um Estado Pós-Moderno? ........................................................................ 35

1.2. Crise do Constitucionalismo? A questão da limitação do poder ............................ 43

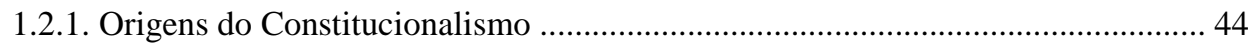

1.2.1.1. Modelos de Constitucionalismo .............................................................. 45

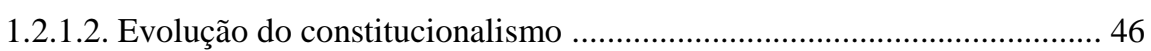

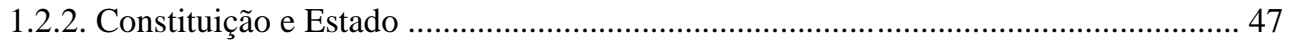

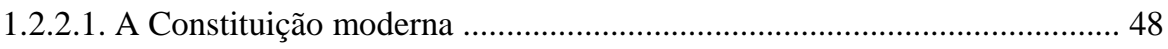

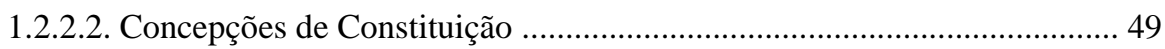

1.2.2.2.1. A Constituição para Lassalle ..................................................... 49

1.2.2.2.2. A Constituição para Kelsen ........................................................ 50

1.2.2.2.3. A Constituição para Schmitt ...................................................... 52

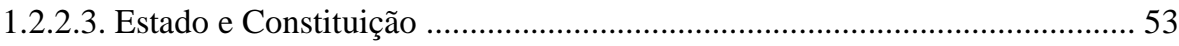

1.2.3. Soberania e Poder Constituinte ......................................................................... 55

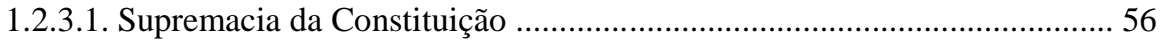

1.2.3.2. Limitações ao Poder Constituinte …………………………………….... 57

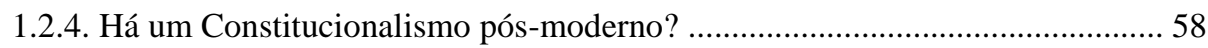

1.3. Crise do direito internacional? A questão do compartilhamento do poder .... 60

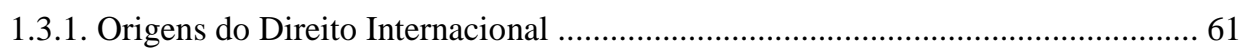

1.3.1.1. Evolução do Direito Internacional ....................................................... 65

1.3.2. Relação entre Direito Internacional e Direito Interno ................................... 66

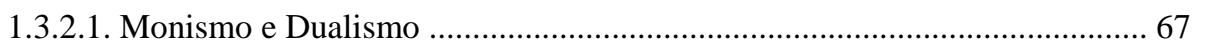

1.3.2.2. Sistemas de relevância do Direito Internacional na Ordem Interna 69

1.3.2.3. Posição da norma internacional na ordem interna 69 
1.3.3. Modelos de convivência internacional 70

1.3.3.1. O modelo Maquiavélico-hobbesiano 70

1.3.3.2. O modelo Grociniano .71

1.3.3.3. O modelo Kantiano 71

1.3.4. Supremacia do Direito Internacional? 72

1.3.4.1. A institucionalização do Direito Internacional 73

1.3.4.2. A Jusfundamentalidade 73

1.4. Crise da Soberania? A questão da legitimação do poder 75

1.4.1. Origens e concepções de Soberania 76

1.4.1.1. Conceito Jurídico e Político de Soberania 82

1.4.1.2. Soberania Nacional, Soberania Popular e Soberania do Estado 85

1.4.1.3. Soberania Interna e Soberania Externa 87

1.4.2. Poder e Direito 88

1.4.2.1. Poder e Direito além do Estado 92

1.4.2.2. Poder e Democracia 94

1.4.3. Globalização e Governança Mundial 95

1.4.3.1. A globalização 96

1.4.3.2. Ordem Transnacional 98

1.4.3.3. Governança Global 99

1.4.4. Relativização da Soberania? 101

1.5. Síntese Conclusiva do Capítulo 1 106

2. MOVIMENTOS DE APROXIMAÇÃO ENTRE O DIREITO CONSTITUCIONAL E O DIREITO INTERNACIONAL 111

2.1. Constitucionalização do Direito Internacional? Globalização e Ordenamento Jurídico Internacional 113

2.1.1. A Expansão das normas de Direito Internacional 116

2.1.1.1. O Adensamento normativo 117

2.1.1.2. A Fragmentação do Direito Internacional 118

2.1.1.3. O Diálogo de Fontes 121

2.1.2. A Institucionalização do Direito Internacional 122

2.1.2.1. O sistema da Organização das Nações Unidas 124

2.1.2.2. O sistema de Bretton Woods 126

2.1.2.3. O Tribunal Penal Internacional 129

2.1.3. A Regionalização do Direito Internacional 131

2.1.3.1. A União Europeia .......................................................................... 132

2.1.3.2. O Mercosul

2.1.3.3. Demais blocos regionais 135

2.1.4. A Proteção Internacional dos Direitos Humanos 136

2.1.4.1. Convenção Europeia e Corte Europeia de Direitos Humanos 138 
2.1.4.2. Pacto de São José da Costa Rica e Corte Interamericana de Direitos Humanos 140

2.1.4.3. Carta Africana e Corte Africana de Direitos Humanos e dos Povos 144

2.2. Internacionalização do direito constitucional? Globalização e Ordenamento Jurídico Nacional 145

2.2.1. Constituição e Direito Internacional 148

2.2.1.1. A relação entre o ordenamento jurídico nacional e o internacional 149

2.2.1.1.1. A primazia do Direito comunitário 152

2.2.1.2. A relação entre Cortes Nacionais e Internacionais 154

2.2.1.2.1. O Princípio da margem nacional de apreciação 155

2.2.2. Controle de Convencinalidade 156

2.2.2.1. Controle de Convencionalidade na Europa 157

2.2.2.2. Controle de Convencionalidade na América-Latina 159

2.2.3. Diálogo entre Cortes 162

2.2.3.1. A Constituição e o Direito Estrangeiro 163

2.2.3.1.1. O uso do direito estrangeiro pelos tribunais norte-americanos 164

2.2.3.2. O Diálogo entre Tribunais Nacionais 169

2.2.3.3. O Diálogo entre Tribunais Nacionais e Regionais 171

2.2.3.4. O Diálogo entre Tribunais Nacionais e Internacionais 174

2.2.4. O Estado Constitucional Cooperativo

2.3. Constitucionalismo Pós-Nacional? Globalização e Ordem Transnacional .... 176

2.3.1. Constitucionalismo Pluralista 178

2.3.1.1. O Constitucionalismo Pluralista de Neil MacCormick 179

2.3.1.2. O Constitucionalismo Pluralista de Neil Walker ... 181

2.3.2. Constitucionalismo Supranacional 183

2.3.2.1. Constitucionalismo Multinível 184

2.3.2.2. Interconstitucionalismo 188

2.3.2.3. Constituições em Rede 193

2.3.3. Direito Transnacional 196

2.3.3.1. O Direito Transnacional de Philip Jessup ..... 197

2.3.3.2. As Constituições Civis Globais de Teubner 200

2.3.3.3. O Direito Transnacional em Rede de K-H Lauder 204

2.3.4. Transconstitucionalismo 208

2.4. Constitucionalismo Mundial?

Globalização

e Ordenamento

Jurídico Mundial. 213

2.4.1. Globalização Judicial 215

2.4.2. Constitucionalismo Global 220 
2.4.3. Constituição Global

2.4.4. Constitucionalização Mundial?

227

2.5. Síntese conclusiva do Capítulo 2 230

3. BREVES COMENTÁRIOS SOBRE A INTERNACIONALIZAÇÃO DO DIREITO CONSTITUCIONAL BRASILEIRO 235

3.1. A abertura do Direito Constitucional brasileiro ao Direito Internacional .... 238

3.1.1. Os Tratados Internacionais no ordenamento jurídico brasileiro ........ 242

3.1.1.1. Os Tratados Internacionais na jurisprudência do STF ............. 242

3.1.1.2. A incorporação dos Tratados de Direitos Humanos .................. 245

3.1.2. A adesão ao Tribunal Penal Internacional .................................................. 245

3.2. O Direito Constitucional brasileiro e a Corte Interamericana de Direitos Humanos 248

3.2.1. Vinculação à jurisprudência da Corte? 250

3.2.1.1. O "diálogo de surdos" envolvendo a Lei de Anistia 253

3.2.1.1.1. A decisão do STF sobre a Lei de Anistia 254

3.2.1.1.2. A decisão da CIDH contra o Brasil 258

3.2.1.1.3. Consequências da decisão da CIDH .261

3.2.1.2. A vinculação à jurisprudência da CIDH sobre direito ao recurso. 262

3.2.2. Medidas Cautelares da CIDH 264

3.2.3. Controle de Convencionalidade no Brasil 266

3.3. STF e Mercosul

3.3.1. Aplicabilidade direta das normas do Mercosul? 271

3.3.2. Cooperação Judicial: Protocolo de Las Leñas 274

3.3.3. Medidas Cautelares 275

3.4. STF e Diálogo Constitucional 276

3.4.1. Referência ao Direito estrangeiro 276

3.4.2. Diálogo entre Cortes 280

3.4.3. Diálogos Transnacionais 281

3.5. Síntese Conclusiva do Capítulo 3 284 


\section{INTRODUÇÃO}

\section{Globalização, Crise do Estado e Crise da Soberania}

A atualidade parece ser caracterizada pela ideia de crise e ruptura. Fala-se em "fim da modernidade", "era da decadência", "fim da história", "fase de transformações". Conforme Frank Richard Pfetsch, já em 1969 John Hertz apontava a "crise do Estadonação", Ernest-Otto Czempiel falava em "soberania anacrônica" e Daniel Bell concluía que o Estado se tornava pequeno para enfrentar os novos problemas da vida contemporânea. O Estado teria se tornado prisioneiro dos processos de europeização, globalização, individualização e renacionalização. ${ }^{1}$

Diante de cenário, economistas, historiadores, sociólogos, filósofos, cientistas políticos e juristas já falam no fim do Estado Moderno, na superação do conceito de soberania e na construção de uma "governança mundial" sem Estado como alternativa para a vida em sociedade. O mundo cibernético, resultado das novas tecnológicas, aparece como principal ferramenta desse processo. Fala-se em sociedade em rede, democracia comunicacional, "república.com", etc... Essas novas formas de organização caracterizamse pela produção de normas sem a identificação de uma fonte única, ligada a uma esfera de poder. Essas normas surgem a partir de interações entre membros da própria sociedade civil. Exemplo disso é o que ocorre com a Internet e com a tentativa de regulá-la. Seriam as novas ordens transnacionais.

A globalização impulsiona, também, a aproximação recíproca entre Direito Internacional e Direito Constitucional, questionando os pressupostos básicos do constitucionalismo moderno que, por inspiração positivista, identificam na Constituição, fruto do poder constituinte, reflexo da soberania do povo, o ápice do ordenamento jurídico do Estado-Nação. No entanto, como bem observa Manoel Gonçalves Ferreira Filho, já Sieyés via no direito natural um limite para a obra do poder constituinte originário:

"O constitucionalismo de cor positivista, de modo geral, não admite haver normas acima da Constituição. É o que se exprime na

\footnotetext{
${ }^{1}$ PFETSCH, Frank Richard. "Capacidade de atuar e legitimação do Estado democrático de direito na era da globalização”, In: Revista Brasileira de Política Internacional, Vol. 41, N. 2, 1998, p. 102-103.
} 
ideia da soberania do Poder Constituinte, eco da soberania do povo, o titular em última instância do Poder. Na verdade, a tese não espelha adequadamente o pensamento de Sieyès. Este, com efeito, admite seja o Constituinte limitado pelos direitos naturais."

Hoje, essa limitação parece estar atrelada igualmente à participação dos Estados em entes supranacionais, como a União Europeia, que faz com que as Constituições desses Estados obedeçam a princípios de ordem internacional. Doutrinadores europeus ${ }^{3}$, inclusive, identificam na União Europeia uma forma de "governança multinível”, na qual o poder público mostra-se difuso e descentralizado, tornando os Estados menos influentes.

Por outro lado, a interferência de normas e instâncias internacionais nas decisões dos Estados, quer no plano internacional, quer no plano nacional, parece colocar em cheque a soberania. Nas palavras de Ferrajoli:

"O Estado nacional como sujeito soberano está hoje numa crise que vem tanto de cima quanto de baixo. (...) O Estado já é demasiado grande para as coisas pequenas e demasiado pequeno para as coisas grandes. (...) Naturalmente, essa crise do Estado é uma crise de época, com consequências imprevisíveis. Mas acreditamos que cabe à cultura jurídica e política apoiar-se naquela 'razão artificial' que é o direito, e que já no passado moldou o Estado em suas relações internas, para indicar as formas e os percursos: os quais passam, evidentemente, através da superação da própria forma do Estado nacional e através da reconstrução do direito internacional, fundamentado não mais sobre a soberania dos Estados, mas desta vez sobre as autonomias dos povos."4

Já Crawford, embora reconheça que a globalização é um forte desafio para a soberania, uma vez que os movimentos de pessoas e capital, ideias e informações, deixam a noção de um Estado soberano cada vez menos real, sustenta que suas bases normativas ainda permanecem:

"Relatórios sobre a morte de soberania são muito exagerados: não só é o estado livre para exercer a sua soberania, a proteção de seus interesses praticamente exige isso. Ele pode entrar em uma variedade de relações políticas que envolvam associação com outros Estados. Ele pode decidir 'reunir' soberanias através de instituições regionais, como a União Europeia - supondo que elas estão disponíveis para ele. Ou pode entrar em acordos substantivos específicos com outros Estados e organizações. Breve integração em grande escala em outro Estado, a sua soberania sobrevive a tais exercícios, refletindo a continua identidade da comunidade

\footnotetext{
${ }^{2}$ FERREIRA FILHO, Manoel Gonçalves. Princípios Fundamentais do Direito Constitucional. 2. Ed. São Paulo: Saraiva, 2010, p. 36.

${ }^{3}$ QUEIROZ, Direito Constitucional Internacional. Lisboa: Coimbra Editora, 2011 p. 55.

${ }^{4}$ FERRAJOLI, Luigi. A Soberania no Mundo Moderno. São Paulo: Martins Fontes, 2002, p. 48-52.
} 
territorial em relação à qual o seu governo deve ser (e às vezes é) responsável." 5

Stephen Krasner observa, no entanto, que a soberania - que é vista como ameaçada pela globalização - corresponde a uma concepção de soberania enquanto controle, não autoridade. Ou seja, a perda de controle do Estado sobre determinada atividade não significa que tenha perdido a autoridade sobre essa área, o seu direito de regular. ${ }^{6}$

II. Constitucionalização do Direito Internacional, Internacionalização do Direito Constitucional e Pluralismo Constitucional

Falar em "deslocação do mundo dos Estados" tornou-se um lugar comum segundo Canotilho. O "novo tempo" seria formado não mais por Estados-nação, mas por “constelações pós-nacionais". Nesse contexto, o Direito Constitucional e o Direito Internacional se confrontam e passa-se a falar em: "direito constitucional integrado", "estados nacionais supranacionais", "estado constitucional cooperativamente aberto", “estados constitucionais abertos”. Já as constituições supranacionalizam-se ou internacionalizam-se. Ou seja, com a integração dos Estados em comunidades supranacionais ou organismos internacionais, os problemas do Estado e da Constituição se integram em um novo "direito constitucional internacional". 7

Nesse cenário, proliferam-se teses sobre a inter-relação entre os diversos “ordenamentos jurídicos constitucionais", que convivem horizontalmente. A Europa, por força da imprecisão conceitual do "espaço europeu”, é o berço das novas ideias: o constitucionalismo pluralista de Neil MacCormick e Neil Walker, o constitucionalismo Multinível de Ingolf Pernice, o Interconstitucionalismo de Lucas Pires ou as ideias de Constituição em rede.

\footnotetext{
${ }^{5}$ CRAWFORD, James. "Sovereignty as legal value", in The Cambridge Companion to International Law. Edited by James Crawford and Martti Koskenniemi. Cambridge University Press, 2012, p. 132: Reports of the death of sovereignty are much exaggerated: not only is the state free to exercise its sovereignty; the protection of its interests practically requires it. It can enter into a variety of political relations involving association with other states. It can decide to 'pool' sovereignty through regional institutions such as the European Union - assuming they are available to it. Or it can enter into specific substantive arrangements with other states and organisations. Short of full-scale integration in another state, its sovereignty survives such exercises of it, reflecting the continued identity of the territorial community to which its government should be (and sometimes is) accountable."

${ }^{6}$ KRASNER, Stephen D. Problematic Sovereignty: contested rules and political possibilities. New York: Columbia University Press, 2001, p. 8.

${ }^{7}$ CANOTILHO, J. J. Gomes. "Brancosos" e Interconstitucionalidade: itinerários dos discursos sobre a historicidade constitucional. Almedina, 2006, p. 284.
} 
Também as concepções de direito transnacional (Philip Jessup, Gralf-Peter Calliess e Karl-Heinz Ladeur), constituições sociais (Teubner) e transconstitucionalismo (Marcelo Neves), baseadas nas ideais de Luhmann, que acabam por influenciar o retorno dos ideais universalistas de Kant, de um constitucionalismo global (Anne Peters) ou uma constituição global (Habermas).

A articulação desses movimentos, desses novos ordenamentos, acaba sendo exercida pelos Tribunais ao redor do mundo, sinal da substituição do gubernaculum pela iurisdictio na esfera global, dando origem às teorias sobre globalização judicial ou judicialização universal (Anne-Marie Slaughter).

Jorge Miranda, por sua vez, entende que esses diferentes processos de relacionamento da ordem interna com outras ordens (supranacionais, regionais, globais, etc...) devem ser estudados por meio de quatro diferentes perspectivas: a do "transconstitucionalismo em nível externo" (direitos fundamentais e direitos humanos; direito da União Europeia e Constituições dos Estados-membros); a do "transconstitucionalismo em nível interno" (recepção de normas e institutos de constituições anteriores; Constituição do Estado Federal e Constituições dos Estados Federados; regime constitucional de minorias e comunidades indígenas); a do "transconstitucionalismo a nível interno por efeito de fatores externos" (limites heterônomos do poder constituinte; heteroconstituições); e a do "interconstitucionalismo" (influência recíproca de certas Constituições; influência recíproca das jurisprudências constitucionais de uns países sobre as de outros). ${ }^{8}$

Independentemente da teoria adotada, a globalização parece apresentar desafios à doutrina constitucional. A atuação das Cortes Internacionais, a importância reconhecida aos tratados internacionais, especialmente aos tratados sobre direitos humanos, a formação de normas que transpassam as realidades nacionais, como a regulação da Internet, a troca de experiências entre cortes internacionais, a formação de novos tipos de associação de Estados, como a União Europeia, parecem questionar a ideia de Constituição como ordenamento jurídico supremo de um Estado soberano.

\section{Objetivos e plano de trabalho}

A pesquisa apresentada tem como tema central o estudo da evolução do Estado e do Constitucionalismo, as possíveis adaptações ao processo de globalização e as

\footnotetext{
${ }^{8}$ MIRANDA, Jorge. Teoria do Estado e da Constituição. $3^{\text {a }}$. Edição. Rio de Janeiro: Forense, 2011, p. 187188.
} 
consequências para o princípio da soberania nacional. Para tanto, o trabalho está dividido em três capítulos.

No primeiro capítulo, parte-se do estudo do Estado para verificar em que medida os elementos do Estado Moderno teriam sido atingidos pela globalização, de modo a transformá-lo em um novo tipo de Estado, afetando sua soberania, e, assim, levando ao desenvolvimento de um novo constitucionalismo. O capítulo, então, divide-se em quatro subcapítulos para melhor analisar as supostas crises do Estado moderno, do Constitucionalismo, do Direito Internacional e, portanto, da Soberania, que perpassa as três anteriores.

No segundo capítulo, busca-se identificar e analisar as principais teorias sobre o mútuo processo de constitucionalização e internacionalização do Direito que, para a doutrina examinada, seria em boa parte consequência da globalização e das "crises" apontadas no primeiro capítulo. Dessa forma, examina as principais características de um Direito Internacional constitucionalizado e de um Direito Constitucional internacionalizado, buscando, a partir daí, sistematizar as novas ordens jurídicas oriundas desse processo e sua relação com o constitucionalismo: ordem transnacional e global.

No terceiro capítulo, por fim, pretende-se demonstrar, a partir do exame de algumas decisões do Supremo Tribunal Federal, a validade das conclusões apontadas nos dois capítulos anteriores para a realidade brasileira: o Estado brasileiro permanece um Estado soberano e a Constituição brasileira continua desempenhando o papel de supremo poder a decidir quais normas incidem no ordenamento jurídico brasileiro e como. Para tanto, a análise da Constituição brasileira e da interpretação que dela faz o Supremo Tribunal Federal parecem a melhor forma de comprovar tais constatações. Neste contexto, abertura constitucional brasileira ao Direito Internacional, as decisões que envolvem, de alguma forma, a Corte Interamericana de Direitos Humanos, a relação existe com o Mercosul e os "diálogos" travados pelo Supremo com o direito estrangeiro e com órgãos decisórios estrangeiros, internacionais e transnacionais. 


\section{CONCLUSÃO}

A globalização, a individualização, a regionalização e a fragmentação da sociedade contemporânea representam novos desafios ao Estado moderno e ao constitucionalismo.

Como visto no capítulo primeiro, em resposta aos problemas de escala global, os Estados estão se associando, cooperando entre si, o que resulta em novas formas de organização e compartilhamento do poder tanto na ordem interna como na internacional.

As novas formas de relacionamento entre os Estados trazem novos desafios tanto para o Direito Constitucional, na medida em que o Estado altera seu funcionamento e finalidade, como para o Direito Internacional, que se vê diante de novos atores, fontes normativas e instituições. Essas mudanças acabam por fortalecer doutrinas internacionalistas, universalistas ou cosmopolitas. Tais doutrinas, inclusive, já conseguem enxergar um mundo sem Estados, ou um Estado Global.

No entanto, parece que a humanidade ainda está longe de alcançar uma República mundial. Embora a globalização tenha acarretado mudanças na vida do indivíduo, da sociedade, do Estado e do mundo, ela não acabou com o Estado.

É bem possível que o Estado moderno esteja entrando em uma nova fase, ainda sem nome, ainda sem características explícitas, mas ainda assim continua o detentor do monopólio da força sobre determinado território.

A grande questão continua sendo a questão do poder. No fim, quem tem o poder de aderir a uma organização ou associação de Estados? Quem delas pode se retirar? Quem define se e em que medida normas produzidas por organizações da sociedade civil, organismos internacionais ou associações de Estados incidirão dentro do território nacional? Parece que a resposta continua sendo o Estado-Nação.

Intimamente ligado ao Estado está o constitucionalismo. Na medida em que o Estado altera suas funções, compartilha sua soberania, relaciona-se com outros Estados e cria novas formas de associações de Estados, o Direito Constitucional também precisa acompanhar essas alterações. Afinal, a história do constitucionalismo é a história da limitação do poder, e isso não parece estar superado. 
Por um lado, a interação entre os Estados leva o constitucionalismo a se adaptar internamente, tornando-se mais aberto, mais cooperativo. Por outro, acaba se projetando para além do Estado, contaminando as esferas supranacional e internacional.

Só que este "constitucionalismo" que se espalha para além do Estado não é propriamente o constitucionalismo moderno, uma vez que não comporta uma Constituição formal, fruto do poder constituinte (povo). Trata-se de um constitucionalismo sem constituição formal, que pode remontar ao constitucionalismo antigo ou prenunciar uma nova forma de constitucionalismo: constitucionalismo transnacional, constitucionalismo social, constitucionalismo global, constitucionalismo multinível, etc.

Por outro lado, a Constituição, internamente, não perdeu sua importância, ao contrário. Apresenta-se como parâmetro de conformação das diversas ordens. E, na medida em que os Estados aprofundam a experiência constitucional, consolidando suas democracias, os princípios do constitucionalismo universal se ampliam. Assim, a garantia dos direitos fundamentais ganha nova escala, a escala mundial.

A comunidade internacional, formada por Estados Constitucionais, que compartilham valores universais, cada vez mais se institucionaliza e fornece novos mecanismos para a resolução pacífica dos conflitos.

Entre os Estados ocidentais, parece que o modelo de convivência internacional, de fato, evoluiu de um modelo Maquiavélico-hobbesiano, bélico, para um modelo grociniano, de sociabilidade e caminha em direção a alcançar o modelo kantiano, de paz universal, justamente em função da evolução do papel dos direitos humanos na esfera mundial.

Mesmo contando cada vez mais com a participação da sociedade civil, esse processo continua pautado pelos Estados. E não poderia deixar de ser assim, dado o déficit democrático ainda presente na arena global.

Sendo assim, a soberania, característica fundamental do Estado, permanece como a base do direito constitucional e do direito internacional. Não há um poder que se afirme acima dos Estados, nem o das Nações Unidas, nem o das associações de Estados como a União Europeia, muito menos o das organizações não governamentais.

É verdade que as feições da soberania não são mais as mesmas. O poder parece ceder cada vez mais espaço ao direito, também nas relações internacionais. 
Se é verdade que o Estado, o Constitucionalismo e a Soberania permanecem, é também verdade que o gubernaculum cada vez mais dá lugar à iurisdictio em um mundo globalizado.

Como visto no segundo capítulo, a complexidade da vida contemporânea alcançou o mundo jurídico. Os processos de mútua implicação entre constitucionalização e internacionalização, guiados sempre pelos valores constitucionais da democracia e da liberdade, surgem ou fortalecem outros ordenamentos jurídicos (além dos tradicionais ordenamentos nacionais e internacional, os locais, regionais, transnacionais...). A liberdade alcançada, por meio das tecnologias contemporâneas, permite trocas entre indivíduos e organizações entre indivíduos que perpassam as fronteiras estatais e desligam-se do poder estatal.

Nesse contexto, velhas práticas constitucionais se intensificam (uso do direito estrangeiro e da jurisprudência de outros tribunais para decidir casos cada vez mais complexos), que agora recebem novos nomes: Diálogo entre Cortes, CrossConstitucionalismo, Fertilização Cruzada...

Mas também novas práticas constitucionais são necessárias como forma de harmonização dos múltiplos ordenamentos que trabalham em diferentes planos. Como se trata de algo ainda em construção, várias doutrinas se desenvolvem, algumas com características muito semelhantes mas com nomes distintos, na tentativa de explicar e, assim, orientar o caminho a ser seguido.

No entanto, a influência das normas internacionais (Sistema da ONU), regionais (União Europeia e Mercosul) ou transnacionais (lei mercatória) nos ordenamentos nacionais de fato ocorre, mas por meio das Constituições.

Ou seja, na medida em que é a ordem constitucional que baliza se e como direitos produzidos fora do Estado produzirão efeitos dentro do Estado, a função da Constituição do constitucionalismo é preservada e a soberania do Estado mantida.

As teorias do "constitucionalismo pós-nacional", por mais que advoguem a redução das constituições nacionais e a existência de constituições em Estados, não conseguiram superar a ideia de que é a Constituição estatal que, no fim, acaba sendo a responsável por conferir alguma legitimidade ou efetividade às outras "constituições".

O Constitucionalismo brasileiro, como visto no capítulo terceiro, pelo menos por enquanto, permanece firme, ao mesmo tempo em que se abre à internacionalização. 
No plano externo, a soberania do Estado brasileiro tem sido reafirmada diuturnamente pelo governo nas suas relações internacionais, como, no plano interno, é constantemente reafirmada pela jurisprudência do Supremo Tribunal Federal.

Tanto em relação ao tratamento dado aos tratados internacionais, quanto em relação ao reconhecimento de decisões de tribunais estrangeiros, regionais ou internacionais, a Constituição brasileira continua sendo, para o Supremo Tribunal Federal, o parâmetro de aferição de validade e aplicação de tais normas e decisões no território nacional, mas sempre sensível à prevalência dos direitos humanos.

De resto, o papel do Supremo Tribunal Federal na harmonização dos múltiplos ordenamentos, à semelhança do que vem sendo desempenhado pelas Tribunais em geral ao redor do mundo, vem crescendo, à medida em que as relações se tornam cada vez mais complexas e o Brasil cada vez mais aberto à esfera internacional. 


\section{BIBLIOGRAFIA}

ALLARD, Julie e GARAPON, Antoine. Les juges dans la mondialisation: la nouvelle revolution du droit. La Republique des Idees Seuil, 2005.

AMARAL JÚNIOR, Alberto do. Introdução ao Direito Internacional Público. São Paulo: Editora Atlas, 2008.

. "Em busca de uma nova perspectiva das fontes de direito internacional", In: Filosofia e Teoria Geral do Direito: homenagem a Tercio Sampaio Ferraz Junior. Org. João Maurício Adeodato e Eduardo C. B. Bittar. São Paulo: Quartier Latin, 2011.

AMARAL JÚNIOR, José Levi Mello do. "O Constitucionalismo", In: Neoconstitucionalismo e atividade jurisdictional: do passivismo ao ativismo judicial. Belo Horizonte: Editora Del Rey, 2012.

. "Tratados e Convenções Internacionais sobre Direitos Humanos e o Pensamento de Celso Lafer", In: Novos Caminhos do Direito no Século XXI: Direito Internacional, Filosofia Jurídica e Política, Dogmática Jurídica e Direitos Fundamentais: Uma homenagem a Celso Lafer. Coordenadores Luiz Olavo Baptista e Tercio Sampaio Ferraz Junior. Curitiba: Juruá, 2012.

ARAÚJO, António de; BRITO, Miguel Nogueira de; e COSTA, Joaquim Pedro Cardoso da. "As relações entre os Tribunais Constitucionais e as outras jurisdições nacionais, incluindo a interferência, nesta matéria, da acção das jurisdições europeias", in

Separata de Estudos em Homenagem ao Conselheiro José Manuel Cardoso da Costa. Tribunal Constitucional. Coimbra Editora, 2003.

ARENDT, Hannah. A Condição Humana. 10a. ed. Rio de Janeiro: Forense Universitária, 2008.

AVBELJ, Matj; KOMÁREK, Jan. Constitutional Pluralism in the European Union and Beyond. Hart Plublishing, Oxford, 2012.

AZAMBUJA, Darcy. Teoria Geral do Estado. 44. Ed. São Paulo: Globo, 2003.

BAHDI, Reem. Globalization of Judgment: transjudicialism, international human rights law and commonealth courts. Thesis degree of LLM. University of Toronto, 2001. 
BAPTISTA, Luiz Olavo. "Análise da funcionalidade do sistema de solução de disputas do Mercosul”, In: Solução de Controvérsias no Mercosul. Brasília: CD/MRE, 2003. Aplicação do direito estrangeiro pelo juiz brasileiro. Revista de Informação Legislativa, Ano 36, N. 142, abr/jun, 1999.

BOBBIO, Norberto. Direito e Estado no pensamento de Emanuel Kant. 2a. ed. São Paulo: Mandarim, 2000. Direito e Poder. Tradução Nilson Moulin. São Paulo: Editora UNESP, 2008.

BODIN, Jean. Los Seis Libros de la República. Tradução de Pedro Bravo Gala. $4^{\mathrm{a}}$ Ed. Espanha: Editorial Tecnos, 2006.

CALLEJÓN, Francisco Balaguer. Derecho Constitucional y Estado en un mundo globalizado. Facultad de Derecho da Universidad de Granada, 24 de janeiro de 2011.

CALLIESS, Gralf-Peter. Law, Transnational. CLPE Research Paper 35/2010, Vol. 06, N. 8 (2010). York University: CLPE Research Paper Series, p. 3. Disponível em: http://ssrn.com/abstracht=1630348.

CANANEA, Giacinto della. "Is European Constitucionalism Really 'Multilevel'?", In: ZaöRV 70 (2010), 283-317.

CANOTILHO, J. J. Gomes. "Brancosos" e Interconstitucionalidade: itinerários dos discursos sobre a historicidade constitucional. Coimbra: Almedina, 2006.

. Direito Constitucional e Teoria da Constituição. 7a. Edição. Coimbra Almedina.

. "Estado de Direito e Internormatividade", In: Direito da União Europeia e Transnacionalidade. Coordenação Alessandra Silveira. Lisboa: Quid Juris Sociedade Editora, 2010.

CARVAlHAL, Ana Paula. Ação Penal no Supremo precisa ser modernizada, In: Coluna Observatório Constitucional. Consultor Jurídico. 21 de setembro de 2013. (http://www.conjur.com.br/2013-set-21/observatorio-constitucional-acao-penalsupremo-modernizada.) Acessado em 15 de janeiro de 2014.

CASELLA, Paulo Borba. "Conceito de Sistema, Contexto Internacional e Pósmodernidade", In: Filosofia e Teoria Geral do Direito: homenagem a Tercio Sampaio Ferraz Junior. São Paulo: Quartier Latin, 2011. 
CASSESE, Sabino. I Tribunali di Babele: I giudici ala ricerca di un nuovo ordine globale. Roma: Donzelli editore, 2009.

A Crise do Estado. Tradução Ilse Paschoal Moreira e Fernanda Landucci Ortale. Campinas, SP: Saberes Editora, 2010.

CASTRO, Cássio Benvenutti de. (Neo)Soberania e Tribunal Penal Internacional. Porto Alegre: Verbo Jurídico, 2011.

CERQUEIRA, Luis Eduardo Bianchi. “Aplicação das Sentenças das Cortes Internacionais no Brasil”, in Revista SJRJ, Vol. 18, No. 32, 2011, pp. 115-134.

CHEVAlLIER, Jacques. O Estado Pós-Moderno. Tradução Marçal Justen Filho. Belo Horizonte: Editora Fórum, 2009.

CONI, Luís Cláudio. A Internacionalização do Poder Constituinte. Porto Alegre: Sergio Antonio Fabris Editor, 2006.

CONTRERAS, Ana Carmona. La tutela supranacional de los derechos en Europa. La Unión europea y la Corte de Luxemburgo. Palestra proferida no Curso de Alta Formação em Justiça Constitucional e Tutela Jurisdicional dos Direitos do Departamento de Jurisprudência da Universidade de Pisa em 23 de janeiro de 2013.

CRAWFORD, James. "Sovereignty as legal value", in The Cambridge Companion to International Law. Edited by James Crawford and Martti Koskenniemi. Cambridge University Press, 2012, pp. 117-133.

CUNHA, Paulo Ferreira da. "Do Constitucionalismo Global", in Revista Brasileira de Direito Constitucional, N. 15, Jan/Jun 2010. . "Repensar a Teoria do Estado Entre Pluralismo Ético e Globalização", in Direito Constitucional Contemporâneo: homenagem ao Professor Michel Temer. São Paulo: Quartier Latin, 2012, pp. 63-70.

DALLARI, Dalmo de Abreu. Elementos de Teoria Geral do Estado. São Paulo: Editora Saraiva, 2011.

DALLARI, Pedro B. A. Constituição e tratados internacionais. São Paulo: Editora Saraiva, 2003.

DELMAS-MARTY, Mireille; e IZORCHE, Marie-Laure. "Marge Nationale d'appréciation et internationalisation du droit. Réflexions sur la validité formelle d'un 
droit commun pluraliste", in Revue Internationale de droit compare, Vol. 52, No. 4, 2000, pp. 753-780.

DOEHRING, Karl. Teoria do Estado. Tradução Castro Alves Araújo. Belo Horizonte: Del Rey, 2008.

FARIA, José Eduardo. O Estado e o direito depois da crise. São Paulo: Saraiva, 2011.

FERRAJOLI, Luigi. A Soberania no mundo moderno: nascimento e crise do Estado Nacional. Tradução Carlo Coccioli e Márcio Lauria Filho. São Paulo: Martins Fontes, 2002.

FERREIRA FILHO, Manoel Gonçalves. O Poder Constituinte. 4. Ed. São Paulo: Saraiva, 2005.

. Estado de Direito e Constituição. 3a . ed. São Paulo: Editora Saraiva, 2004.

. A Democracia no Limiar do Século XXI. São Paulo: Saraiva, 2001.

. Princípios Fundamentais do direito constitucional. 2. Ed. São Paulo: Saraiva,

2010.

. Do Processo Legislativo. 7. Ed. Rev. e Atual. São Paulo : Saraiva, 2012.

. Comentários à Constituição Brasileira de 1988. São Paulo: Saraiva, 1990,

Vol. 1, p. 18-19.

FORJAZ, Maria Cecília Spina. “Globalização e Crise do Estado Nacional”, In: Revista de Administração de Empresas - RAE, Vol. 40, No. 2, abr/jun 2000.

FURLAN, Fernando de Magalhães. "A Supranacionalidade no Mercosul”, in Revista Brasileira de Direito Constitucional - RBDC, No. 15, jan/jun de 2010, pp. 91-124.

GAMBINO, Silvio. I Diritti Fondamentali in Europa. Palestra proferida no Curso de Alta Formação em Justiça Constitucional e Tutela Jurisdicional dos Direitos do Departamento de Jurisprudência da Universidade de Pisa em janeiro de 2013.

GISBERT, Rafael Bustos. La Constitución Red: un estudio sobre supraestatalidad y constitución. Oñati: Instituto Vasco de Administración Pública, 2005.

GOZZI, Gustavo. "Estado Contemporâneo", In: Dicionário de Política. BOBBIO, Norberto; MATTEUCCI, Nicola; PASQUINO, Gianfranco. Tradução de Carmen C. Varriale. 5a. ed. Brasília: Editora Universidade de Brasília: São Paulo: Imprensa Oficial do Estado, 2000. Vol. I. 
GRIMM, Dieter. The Achievement of Constitutionalism and it Prospects in a Changed World, In: The Twilight of Constitutionalism?. Edted by Petra Dobner and Martin Loughlin. Oxford University Press, 2010.

GROPPI, Tania. Seminario conclusive: El futuro de los derechos fundamentales: una visión comparada. Palestra proferida no Curso de Alta Formação em Justiça Constitucional e Tutela Jurisdicional dos Direitos do Departamento de Jurisprudência da Universidade de Pisa em 23 de janeiro de 2013.

HÄBERLE, Peter. El Estado Constitucional. Universidad Nacional Autónoma de México, 2001.

HABERMAS, Jürgen. A Constelação pós-nacional: ensaios politicos. Tradução Márcio Seligmann-Silva. São Paulo: Littera Mundi, 2001.

HELD, David. “A Democracia, o Estado-Nação e o Sistema Global”, In: Lua Nova, No. 23, março 1991.

HOBBES, Thomas. Leviatã, ou, A material, forma e poder de um Estado Eclesiástico e Civil. Tradução Rosina D’Angina. São Paulo, Ícone, 2008.

HÖFFE, Otfried. A Democracia no mundo de hoje. Tradução Tito Lívio Cruz Romão. São Paulo: Martins Fontes, 2005.

HORBACH, Carlos Bastide. "Referências estrangeiras são constantes no STF”, In: Coluna Observatório Constitucional. Consultor Jurídico, 10 de novembro de 2012: http://www.conjur.com.br/2012-nov-10/observatorio-constitucional-referenciasestrangeiras-sao-constante-stf.

JESSUP, Philip. Transnational Law (1956), p. 136, apud SCOTT, Craig. "Transnational Law as Proto-Concept: Three Conceptions", In: German Law Journal, Vol. 10, N. 7 , 2009

JULIOS-CAMPUZANO, Afonso de. Constitucionalismo em Tempos de Globalização. Tradução Jose Luis Bolzan de Morais e Valéria Ribas do Nascimento. Porto Alegre: Livraria do Advogado, 2009.

KANT, Immanuel. A Metafísica dos Costumes. Tradução José Lamego. Fundação Calouste Gulbenkian.

KELSEN, Hans. Teoria Pura do Direito. São Paulo: Martins Fontes, 1998. 
KILLANDER, Magnus. Interpretação dos Tratados Regionais de Direitos Humanos. SUR International Journal on Human Rights, Vol. 7, N. 13, dez. 2010. Disponível em: http://papers.ssrn.com/sol3/papers.cfm?abstract_id=1923206.

KLABBERS, Jan. "Setting the Scene", In: The Constitutionalization of International Law. KLABBERS, Jan; PETERS, Anne; e ULFSTEIN, Geir. Oxford: Oxford University Press, 2009.

KOSKENNIEMI, Martti. "What Use for Sovereignty Today?", in Asian Journal of International Law, Vol. I, 2011, pp. 61-70.

KRISCH, Nico. Beyond Constitutionalism: The Pluralist Structure of Postnational Law. Oxford University Press, 2010.

• "Postnational Constitutionalism?", In: Hauser Globalization Colloquium FALL 2008: Global Governance and Legal Theory. NYU Law School, p. 1. Disponível em: http://iilj.org/courses/2008HauserColloquium,asp.

LAFER, Celso. A Internacionalização dos Direitos Humanos. Barueri: Manole, 2005. . “A Soberania e os Direitos Humanos”, In: Lua Nova, N. 35-95. . O Convênio do Café de 1976. São Paulo: Editora Perspectiva, 1979. . A OMC e a regulamentação do comércio internacional: uma visão brasileira. Porto Alegre: Livraria do Advogado, 1998.

. Comércio, desarmamento, direitos humanos: reflexões sobre uma experiência diplomática. São Paulo: Paz e Terra, 1999.

. Norberto Bobbio: trajetória e obra. São Paulo: Perspectiva, 2013.

. Entre a norma e a realidade. Entrevista para a Revista Cult em 14 de março de 2010 .

. "Prefácio", In: Controle de Constitucionalidade da Lei Estrangeira. Gustavo Ferraz de Campos Monaco. São Paulo: Quartier Latin, 2013.

LADEUR, Karl-Heinz. "Towards a Legal Theory of Supranationality - The Viability of the Network Concept”, In: European Law Journal, Vol. 3, N. 1, March 1997 . "European Law as Transnational Law: Europe has to be conceived as an Heterarchical Network and Not as a Superstate!”, in German Law Journal, Vol. 10, No. 10, 2009, pp. 1357-1365. 
. "The State in International Law”, In: CLPE Research Paper Series, Vol. 6, N. 6,2010

LASSALLE, Ferdinand. A Essência da Constituição. 6a. ed. Rio de Janeiro: Lumen Juris, 2001.

LEWANDOWSKI, Enrique Ricardo. Globalização, Regionalização e Soberania. São Paulo: Editora Juarez de Oliveira, 2004.

LOCKE, John. Segundo Tratado sobre o Governo Civil. Tradução Magda Lopes e Marisa Lobo da Costa. Rio de Janeiro: Editora Vozes.

LOEWENSTEIN, Karl. Teoria da Constituição. Tradução Alfredo Gallego Anabitarte. Barcelona: Editorial Ariel, 1986.

LUCIANI, Massimo. Seminario conclusivo: El futuro de los derechos fundamentales: una visión comparada. Palestra proferida no Curso de Alta Formação em Justiça Constitucional e Tutela Jurisdicional dos Direitos do Departamento de Jurisprudência da Universidade de Pisa em 23 janeiro de 2013.

MACCORMICK, Neil. "Beyond the Sovereign State”, In: The Modern Law Review, Vol. 56, N. 1, jan/1993.

MACHADO, Jónatas E. M. Direito Internacional. 4a. Ed. Coimbra Editora, 2013.

MALBERG, R. Carré de. Teoría General del Estado. Tradução de José Lión Depetre.Facultad de Derecho UNAM. México: Fondo de Cultura Económica, 1998.

MALISKA, Marcos Augusto. Estado e Século XXI: a integração supranacional sob a ótica do Direito Constitucional. Rio de Janeiro: Renovar, 2006.

MAQUIAVEL, Nicolau. O Príncipe. Tradução Lívio Xavier. São Paulo: Ediouro, 2002.

MARQUES, Claudia Lima. "Direito do Consumidor entre Direito Nacional e o Internacional", In: Transnacionalidade do Direito: Novas perspectivas dos conflitos entre ordens jurídicas. Coord. Marcelo Neves. São Paulo: Quartier Latin, 2010.

MATTEUCCI, Nicola. Organización Del Poder y Libertad: historia del constitucionalismo moderno. Madrid: Editorial Trotta, 1998.

. El Estado Moderno: léxico y exploraciones. Unión Editorial, 2010.

. "Constitucionalismo", In: Dicionário de Política. BOBBIO, Norberto; MATTEUCCI, Nicola; PASQUINO, Gianfranco. Tradução de Carmen C. Varriale. 
5a. ed. Brasília: Editora Universidade de Brasília: São Paulo: Imprensa Oficial do Estado, 2000. Vol. I.

- "Contratualismo", In: Dicionário de Política. BOBBIO, Norberto; MATTEUCCI, Nicola; PASQUINO, Gianfranco. Tradução de Carmen C. Varriale. 5a. ed. Brasília: Editora Universidade de Brasília: São Paulo: Imprensa Oficial do Estado, 2000. Vol. I.

. "Soberania", In: Dicionário de Política. BOBBIO, Norberto; MATTEUCCI,

Nicola; PASQUINO, Gianfranco. Tradução de Carmen C. Varriale. 5a. ed. Brasília:

Editora Universidade de Brasília: São Paulo: Imprensa Oficial do Estado, 2000. Vol. II.

MAZZUOLI, Valerio de Oliveira. O Controle Jurisdicional da Convencionalidade das Leis. São Paulo: Editora Revista dos Tribunais, 2009.

MCILWAIN, Charles H. Costituzionalismo antico e moderno. Bologna: Il Mulino, 1990.

MELLO, Celso D. Albuquerque. Direito Constitucional Internacional. São Paulo: Renovar, 2000.

MENDES, Gilmar Ferreira; BRANCO, Paulo Gustavo Gonet. Curso de Direito Constitucional. 6a . ed. São Paulo: Saraiva, 2011.

MENDES, Gilmar Ferreira; GALINDO, George Bandeira. Direitos Humanos e Integração Regional: algumas considerações sobre o aporte dos tribunais constitucionais. Disponível em: http://www.stf.jus.br/arquivo/cms/sextoEncontroConteudoTextual/anexo/Brasil.pdf

MENDES, Gilmar. “A Justiça Constitucional nos Contextos Supranacionais”, In: Transnacionalidade do Direito: Novas perspectivas dos conflitos entre ordens jurídicas. Coord. Marcelo Neves. São Paulo: Quartier Latin, 2010..

Apresentação do livro "A Força Normativa da Constituição" de Konrad Hesse. Porto Alegre: Sergio Antonio Fabris Editor, 1991.

MENÉNDEZ, Agustín José. "From Constitutional Pluralism to a Pluralistic Constitution?:

Constitutional Synthesis as a MacCormickian Constitutional Theory of European Integration”, In: RECON Online Working Paper 2011/02, p. 11. Disponível em: http://www.reconproject.eu/projectweb/portaalproject/RECONWorkingPapers.html. 
MENEZES, Fabiano L. de. Um olhar crítico da nova ordem mundial de Slaughter, In: $3^{\circ}$ ENCONTRO NACIONAL ABRI, 2011, São Paulo. Associação Brasileira de Relações Internacionais, Instituto de Relações Internacionais - USP, Disponível em: http://www.proceedings.scielo.br/scielo.php?script=sci_arttext\&pid=MSC000000012 2011000200004\&lng=en\&nrm=abn.

MENEZES, Wagner. Tribunais Internacionais: jurisdição e competência. São Paulo: Saraiva, 2013.

MEZZETTI, Luca. La tutela sovranazionale dei diritti in Europa. La Convenzione europea dei diritti dell'uomo e la Corte di Strasburgo. Palestra proferida no Curso de Alta Formação em Justiça Constitucional e Tutela Jurisdicional dos Direitos do Departamento de Jurisprudência da Universidade de Pisa em 23 janeiro de 2013.

MILLS, Alex; e STEPHENS, Tim. "Challenging the Role of Judges in Slaughter's Liberal Theory of International Law", in Leiden Journal of International Law, 18, 2005, pp. $1-30$.

MIRANDA, João Irineu de Resende. O Tribunal Penal Internacional frente ao princípio da soberania. Londrina: Eduel, 2011.

MIRANDA, Jorge. Curso de Direito Internacional Público. 4. Ed. Portugal: Princípia, 2009.

. Teoria do Estado e da Constituição. 3. Ed. Rio de Janeiro: Forense, 2011. . Contributo para uma teoria da Inconstitucionalidade. Coimbra Editora, 1996.

MONACO, Gustavo Ferraz de Campos. Controle de Constitucionalidade da Lei Estrangeira. São Paulo: Quartier Latin, 2013, p. 27.

MONTESQUIEU, Charles Louis de Secondat, baron de la Brède et de. O Espírito das Leis. Tradução de Fernando Henrique Cardoso e Leôncio Martins Rodrigues. Brasília: Editora Universidade de Brasília, 1995.

NEVES, Marcelo. Transconstitucionalismo. São Paulo: USP, 2009.

PAGLIARINI, Alexandre Coutinho. "Constituição Supranacional: Uma Internacionalização do Direito Constitucional?”, in Revista Direitos Fundamentais \& Democracia, Vol. 5, 2009. 
PANNUNZIO, Eduardo. A judicialização das relações internacionais no Brasil em face do princípio constitucional da prevalência dos direitos humanos. Tese de doutorado. Faculdade de Direito da USP, 2012.

PERNICE, Ingolf. "Multilevel Constitutionalism and the treaty of Amsterdam: European Constitution-making revisited?", In: Common Market Law Review 36, 199, WHIPaper 4/99. Disponível em: http://whi-berlin.de/documents/whi-paper0502.pdf

"The Treaty of Lisbon: Multilevel Constitutionalism Action. Berlin/Princeton, 2009. WHI-Paper 02/09. Disponível em: www.whiberlin.de/documents/whi-paper0209.pdf.

PERRONE-MOISÉS, Cláudia. “A relação entre tribunais nacionais e tribunais penais internacionais", in Boletim do Instituto Brasileiro de Ciências Criminais, São Paulo, 2000, pp. 13-14.

- "Leis de Anistia em face do direito internacional - desaparecimentos e direito à verdade", in Revista OAB/RJ, Vol. 24, No. 1, 2008, pp. 27-53.

PETERS, Anne. Global Constitutionalism. Palestra proferida em 11 de julho de 2012 no Summer Seminar on Public International Law and Human Rights na Faculdade de Direito da Universidade de Coimbra, Portugal.

. The Merits of Global Constitutionalism, In: Indiana Journal of Global Legal Studies. Vol. 16 (Summer 2009).

- Membership in the Global Constitutional Community, In: The Constitutionalization of International law. KLABBERS, Jan; PETERS, Anne; ULFSTEIN, Geir. Oxford University Press, 2009.

Dual Democracy, In: The Constitutionalization of International law. KLABBERS, Jan; PETERS, Anne; ULFSTEIN, Geir. Oxford University Press, 2009

PFETSCH, Frank Richard. "Capacidade de atuar e legitimação do Estado democrático de direito na era da globalização”, In: Revista Brasileira de Política Internacional, Vol. 41, N. 2, 1998.

PIOVESAN, Flávia. Direitos Humanos e o Direito Constitucional Internacional. 12 ed. São Paulo: Saraiva, 2011. 
Direitos Humanos e Justiça Internacional. 3a. ed. São Paulo: Editora Saraiva, 2012.

PIRES, Francisco Lucas. Introdução ao Direito Constitucional Europeu. Coimbra: Livraria Almedina, 1997.

QUEIROZ, Cristina. Direito Constitucional Internacional. Lisboa: Coimbra Editora, 2011.

RAMOS, André de Carvalho. “A interpretação internacional dos direitos humanos: choque ou diálogo com o Supremo Tribunal Federal?”, In: Novos Caminhos do Direito no Século XXI: Direito Internacional, Filosofia Jurídica e Política, Dogmática Jurídica e Direitos Fundamentais: Homenagem a Celso Lafer. Coordenação Luiz Olavo Baptista e Tercio Sampaio Ferraz Junior. Curitiba: Juruá Editora, 2012.

. "Pluralidade das ordens jurídicas: uma nova perspectiva na relação entre o direito internacional e o direito constitucional", In: Revista da Faculdade de Direito da USP, Vol. 106/107, jan./dez. 2011/2012.

- "Supremo Tribunal Federal e o controle de convencionalidade: levando a sério os tratados de Direitos Humanos", In: Revista da Faculdade de Direito da UPS, Vol. 104, 2009.

. "O DIÁlOGO DAS CORTES: O SUPREMO TRIBUNAL FEDERAL E A CORTE INTERAMERICANA DE DIREITOS HUMANOS", In: O STF e o DIREITO INTERNACIONAL DOS DIREITOS HUMANOS. Org. Alberto do Amaral Junior e Liliana Lyra Jubilut. São Paulo: Quartier Latin, 2009.

RAMOS, Rui Manuel Moura. "Panorama do Direito Internacional Privado Contemporâneo", In: Novos Caminhos do Direito no Século XXI: direito internacional, filosofia jurídica e política, dogmática jurídica e direitos fundamentais: uma homenagem a Celso Lafer. Coord. Luiz Olavo Batista e Tercio Sampaio Ferraz Junior. Curitiba: Juruá Editora, 2012.

RANGEL, Paulo Castro. 'Uma Teoria da 'Interconstitucionalidade' (pluralismo e constituição no pensamento de Francisco Lucas Pires), in THEMIS - Revista da Faculdade de Direito da Universidade Nova de Lisboa, Ano I, No. 2, Almedina, 2000 pp. $127-151$.

RANIERI, Nina Beatriz Stocco. Teoria do Estado: do Estado de Direito ao Estado Democrático de Direito. Barueri, SP : Manole, 2013. 
REALE, Miguel. Teoria do Direito e do Estado. 5. Ed. São Paulo: Saraiva, 2000.

REGONINI, Glória. "Estado do Bem-Estar", In: Dicionário de Política. BOBBIO, Norberto; MATTEUCCI, Nicola; PASQUINO, Gianfranco. Tradução de Carmen C. Varriale. 5a. ed. Brasília: Editora Universidade de Brasília: São Paulo : Imprensa Oficial do Estado, 2000. Vol. I.

RICUPERATI, Giuseppe. "Cosmopolitismo", In: Dicionário de Política. BOBBIO, Norberto; MATTEUCCI, Nicola; PASQUINO, Gianfranco. Tradução de Carmen C. Varriale. 5a. ed. Brasília: Editora Universidade de Brasília: São Paulo: Imprensa Oficial do Estado, 2000. Vol. I.

RODRIGUES JUNIOR, Otavio Luiz. "Fonte estrangeira pode fundamentar decisão nacional?, In: Coluna Direito Comparado. Consultor Jurídico. 12 de dezembro de 2012. Disponível em: http://www.conjur.com.br/2012-dez-12/direito-comparadorecurso-estrangeiro-fundamentar-decisa-nacional. Acessado em 15 de janeiro de 2013.

ROUSSEAU, J. J. Do Contrato Social: princípios de direito político. Tradução J. Cretella Jr e Agnes Cretella. São Paulo: Editora Revista dos Tribunais, 2002.

RUFFÌA, Paolo Biscaretti di. Introducción al derecho constitucional comparado: Las "formas de Estado" y las "formas de gobierno". Las Constituciones modernas. México: Fondo de Cultura Económica, 1996.

SABADELL, Ana Lucia; DIMOULIS, Dimitri. “O Tribunal Penal Internacional em face da Constituição Brasileira e a questão da Ineficácia Social dos Direitos Fundamentais", In: Transnacionalidade do Direito: novas perspectivas dos conflitos entre ordens jurídicas. Coordenação de Marcelo Neves. São Paulo: Quartier Latin, 2010.

SALDANHA, Nelson. O Estado Moderno e a Separação de Poderes. 2a. Edição. São Paulo: Quartier Latin, 2010.

SARLET, Ingo. A Eficácia dos Direitos Fundamentais. $3^{\text {a }}$ Ed. Porto Alegre: Livraria do Advogado, 2003.

SCHIERA, Pierangelo. "Estado Moderno”, In: Dicionário de Política. BOBBIO, Norberto; MATTEUCCI, Nicola; PASQUINO, Gianfranco. Tradução de Carmen C. Varriale. 
5a. ed. Brasília: Editora Universidade de Brasília: São Paulo: Imprensa Oficial do Estado, 2000. Vol. I.

SCHIPANI, Sandro. "Harmonização e unificação do Direito - Direito Comum em matéria de obrigações e contratos na América Latina", In: Novos Caminhos do Direito no Século XXI: direito internacional, filosofia jurídica e política, dogmática jurídica e direitos fundamentais: homenagem a Celso Lafer. Organização Luiz Olavo Baptista e Tercio Sampaio Ferraz Junior. Curitiba: Juruá, 2012.

SCHMITT, Carl. Teoría de la Constitución. Madrid: Alianza Editorial, 2003.

SCOTT, Craig. “"Transnational Law' as Proto-Concept: Three Conceptions”, In: German Law Journal, Vol. 10, N. 7, 2009, pp. 859-876.

SHAW, Malcolm N. International Law. 6a. ed. Cambridge, 2008.

SIEYÈS, Emmanuel. Que es el tercer estado?: Ensayo sobre los privilégios. Madrid: Alianza Editorial, 1989.

SILVA, Virgílio Afonso da. "Colisões de direitos fundamentais entre ordem nacional e ordem transnacional", In: Transnacionalidade do Direito: Novas perspectivas dos conflitos entre ordens jurídicas. Coord. Marcelo Neves. São Paulo: Quartier Latin, 2010.

- "Integração e diálogo constitucional na América do Sul”, In: Direitos humanos, democracia e integração jurídica na América do Sul. Organizado por Armin von Bogdandy, Flávia Piovesan e Mariela Morales Antoniazzi. Rio de Janeiro: Lumen Juris, 2010

SLAUGHTER, Anne-Marie. "Judicial Globalization”, in Virginia Journal of International Law, Vol. 40, 1999-2000, pp. 1103-1124.

. A New World Order. Princeton University Press, 2004.

SOUZA JUNIOR, Cezar Saldanha. Consenso e Tipos de Estado no Ocidente. Porto Alegre: Editora Sagra Luzzatto, 2002.

A Supremacia do Direito no Estado Democrático e seus Modelos Básicos. Tese para Concurso a Professor Titular junto ao Departamento de Direito do Estado da Faculdade de Direito da USP. Porto Alegre, 2002. 
O Tribunal Constitucional como poder: uma nova teoria da divisão dos poderes. São Paulo: Memória Jurídica Editora, 2002.

SPADA, Paolo. Regole e giurisdizioni in concorrenza: il crepuscolo dela sovranità. Facoltà di Giurisprudenza da Università degli Studî Suor Orsola Benincasa: Editoriale Scientifica, 2009.

SPERTI, Angioletta. "Il dialogo tra le Corti Costituzionali ed il ricorso ala comparazione giuridica nella esperienza più recente", in Rivista di Diritto Costituzionale. G. Giappichelli Editore. Tornino, 2006, pp. 125-165.

STOPPINO, Mario. "Poder”, In: Dicionário de Política. BOBBIO, Norberto; MATTEUCCI, Nicola; PASQUINO, Gianfranco. Tradução de Carmen C. Varriale. 5a. ed. Brasília: Editora Universidade de Brasília: São Paulo: Imprensa Oficial do Estado, 2000. Vol. I.

SUNSTEIN, Cass R. A Constitution of Many Minds. Princeton University Press, 2009.

TEUBNER, Gunther. Constitutional Fragments: Societal Constitutionalism and Globalization. Oxford, 2012. . "Fragmented Foundations", In: The Twilight of Constitutionalism? Petra Dobner e Martin Loughlin. Oxford University Press, 2010.

TRINDADE, Antônio Augusto Cançado. Os Tribunais Internacionais contemporâneos e a busca da realização do ideal da justiça internacional. Rev. Fac. Direito UFMG, Belo Horizonte, n. 57, p. 37-68, jul/dez 2010.

TUSHNET, Mark. "The Inevitable Globalization of Constitutional Law", in Virginia Journal of International Law, Vol. 49, 2009.

VALLE, Rubén Hernández. Las sentencias básicas de la Corte Interamericana de Derechos Humanos. Madrid: Centro de Estudios Políticos y Constitucionales, 2011. La Tutela supranacional de los derechos en América. La experiencia de la Corte Interamericana. Palestra proferida no Curso de Alta Formação em Justiça Constitucional e Tutela Jurisdicional dos Direitos do Departamento de Jurisprudência da Universidade de Pisa em janeiro de 2013.

VARELLA, Marcelo D. “As Transformações do Direito Internacional e Algumas Visões sobre um eventual processo de constitucionalização", in Direito Constitucional 
Contemporâneo: homenagem ao Professor Michel Temer. São Paulo: Quartier Latin, 2012.

- Internacionalização do Direito: Direito Internacional, Globalização e Complexidade. Tese de Livre-Docência em Direito Internacional apresentada na Faculdade de Direito da USP. São Paulo, 2012.

. Direito Internacional Público. São Paulo: Editora Saraiva, 2009.

VERGOTTINI, Giuseppe de. Il dialogo transnazionale fra le Corti. Facoltà di Giurisprudenza da Università degli Studî Suor Orsola Benincasa: Editoriale Scientifica, 2010.

VIELLECHNER, Lars. “The Network of Networks: Karl-Heinz Ladeur's Theory of Law and Globalization”, In: German Law Journal, Vol. 10, N. 04, 2009.

WALDRON, Jeremy. "Foreign Law and The Modern Ius Gentium", in Harvard Law Review, Vol. 119, 2005.

WALKER, Neil. "Beyond the Holistic Constitution?", In: The Twilight of Constitutionalism? Edited by Petra Dobner and Martin Loughlin. Oxford University Press, 2010 . "Reframing EU Constitutionalism", In: Ruling the World? Constitutionalism, International Law, and Global Governance. Edited by Jeffrey L. Dunoff and Joel P. Trachtman. Cambridge University Press, 2009 . "The Migration of Constitutional Ideas and the Migration of the Constitutional Idea: the Case of the EU", in EUI Working Paper Law No. 2005/04. Italy: European University Institute, 2005. . The Idea of Constitutional Pluralism. EUI Working Paper Law N. 2002/1. Itália: European University Institute, 2002

WUERTH, Ingrid. “Transnationalizing Public Law”, in German Law Journal, Vol. 10, No. 10, 2009, pp. 1337-1340.

ZUMBANSEN, Peer. "Transnational Law”, in Comparative Research in Law \& Political Economy, CLPE Research Paper 09/2008, Vol. 4, N. 2, pp. 738-754. 